\title{
Provérbios e Expressões Proverbiais em Português e Italiano
}

\section{Maria Romano Schreiber \\ e \\ Íria Maria Renault de Castro Silva}

"Paese che vai, usanza che trovi", diz um provérbio italiano. De fato, os usos de cada povo são, muitas vezes, manifestados por meio de provérbio, alguns deles muito característicos e cheios de sabedoria. Um compilador de provérbios, Augusto Arthaber em seu valioso Dizionario Comparato di Proverbi e Modi Proverbiali (1) * afirma que "veri monumenti orali, gran parte dei proverbi portano impresso lo stampo ed il carattere d'un popolo, del quale, ben più che la storia, ne chiariscono gli usi, il modo di vedere, di sentire, di pensare e di giudicare. E non é assurdo pertanto l'asserire che chiunque voglia indagare come un popolo pensi e come senta, quale sia il suo ingegno e la sua naturale accortezza, non può fare a meno di studiarne gli assiomi proverbiali". Como epígrafe da obra acima encontramos a seguinte citação de Niccolò Tommaseo, um dos maiores estudiosos deste assunto na Itália, no século passado: "Se tutti si potessero raccogliere e sotto certi capi ordinare i proverbi d'ogni popolo e d'ogni età, colle varianti di voci, d'immagini e di concetti; questo, dopo la Bibbia sarebbe il libro più gravido di pensieri".

* Os números entre parênteses correspondem à bibliografia na ordem em que foi organizada e que se encontra no fim do texto. 
Muitos estudos já foram feitos, englobando compilações e listagens de provérbios, entre diferentes línguas, contudo não nos foi possível encontrar nada que colocasse, lado a lado, ditados em italiano e português. Além disto, em toda a bibliografia a que temos acesso, quase não há comentários sobre o sentido dos ditos populares, nem sobre as diferenciações nas várias línguas. A partir disto pensamos que seria interessante um estudo comentado de provérbios das duas línguas, de onde se poderia obter uma gama de informações a respeito dos dois povos. No trato com os estudantes a experiência nos tem mostrado que o estudo dos provérbios é um recurso didático de grande valia, especialmente pela simpatia com que tal assunto é recebido.

Por se tratar de um campo muito vasto, tivemos de nos limitar ao estudo de alguns temas que achamos mais sugestivos pois, para citar apenas um exemplo, uma das obras consultadas Proverbi Toscani, de Fortunato Bellonzi,(2) elenca nada menos que 2.632 provérbios, número tanto mais considerável, quando se leva em conta que o autor trata somente de uma região da Itália, a Toscana.

Os provérbios foram agrupados levando em conta o próprio tema, adotando dentro deste a palavra chave, o que nos pareceu fornecer uma maneira fácil e direta de recuperação da informação.

Não consideramos os ditados que são simples traduções literais da outra língua, como por exemplo: "Pé de galinha não mata pintinho" - "Piede di gallina non uccide pulcino".

Passando à definição de provérbios, achamos ainda válido o que nos diz Niccolò Tommaseo em seu Dizionario della lingua italiana: (14) "detto breve e arguto e ricevuto comunemente, che per lo più sotto parlar figurato compreende avvertimenti attinenti al vivere umano".

Aurélio Buarque de Holanda, no Novo Dicionário da Língua Portuguesa, (5) define o provérbio como "máxima ou sentença de caráter prático e popular, comum a todo um grupo social, expressa em forma sucinta e geralmente rica em imagens". Além destas duas definições clássicas, achamos interessante transcrever aqui o que as crianças pensam a respeito dos provérbios na coletânea organizada por Matizia Maroni Lumbroso Proverbi e modi di dire trascritti e illustrati da bambini italiani e stranieri. (9) Uma criança 
de Trento (Itália) acha que o provérbio é "una formula scoperta dagli uomini primitivi"; em Lanciano, província de Chieti, um aluno de escola elementar expressa-se do seguinte modo: "tanta gente non muore perché crede ai proverbi e non muore perché prima di fare una cosa vede se c'è il proverbio che dice di sí o di no". E interessante notar também a observação da organizadora da coletânea acima citada, quando diz na "Introdução" que é como intuição-pressentimento que as crianças sentem os provérbios.

A mesma idéia de sabedoria e de utilidade para a vida contida nos ditados aparece em dois famosos romancistas italianos do século passado, Alessandro Manzoni e Giovanni Verga. O primeiro quando coloca na boca de uma personagem de I Promessi Sposi (8) a seguinte afirmação: " $\mathrm{E}$ i proverbi, signor conte, sono la sapienza del genere umano".

Verga, fazendo apresentação do protagonista de seu romance I Malavoglia, (15) assim se expressa "Padron 'Ntoni sapeva anche certi motti e proverbi che aveva sentito dagli antichi "perché il motto degli antichi mai menti" - "Senza pilota barca non cammina" - ... Ecco perché la casa del nespolo prosperava e Padron 'Ntoni passava per testa quadra, al punto che a Trezza l'avrebbero fatto consigliere comunale".

Quanto à formulação, os provérbios se expressam na maioria das vezes em linguagem popular, tanto que o lingüista Rohlfs em seus Studi e Ricerche su Lingua e dialetti d'Italia, (13) para ilustrar a incrivel diversidade das línguas neolatinas que se desenvolveram na Itália escolheu, "alcuni proverbi, dato che i motti popolari nella loro breve e semplice forma rispecchiano più genuinamente il linguaggio del popolo".

Neste nosso estudo, agrupamos os provérbios por tema em doze categorias, a saber:

1. Agricultura-Animais

2. Homem-Mulher

3. Família

4. Pátria

5. Lucro

6. Velhice 
7. Pobreza-Riqueza

8. Religião

9. Vinho

10. Anatomia

11. Profissões

12. Vários

Estudamos à parte, sem incluir nas categorias acima, provérbios sem correspondente em uma das duas línguas.

\section{I - AGRICULTURA-ANIMAIS}

Ägua

1. Ảgua mole em pedra dura, tanto bate até que fura.

A goccia a goccia s'incava la pietra.

As duas línguas expressam o mesmo conceito, mas de maneira diferente. O italiano, reproduzindo quase textualmente o latim "Gutta cavat lapidem", encontrado em Ovídio, Lucrécio, Tibullo e Sêneca, é mais requintado e sintético. O português é mais popular, contrapondo os adjetivos "mole" e dura" e apresentando rima, recurso muito eficaz em ditados.

\section{Andorinha}

2. Uma andorinha só não faz verão.

Una rondine non fa primavera.

O italiano, assim como o grego, o latim e o francês, usa o vocábulo "primavera", ao passo que o português, o espanhol e o alemão empregam "verão" para o mesmo provérbio.

Um ornitologista brasileiro consultado a este respeito informou que a migração das andorinhas em todos os países da Eupora se dá ao mesmo tempo, na primavera. As variantes "primavera" e "verão" não teriam, pois, uma justificação científica, como chegamos no começo a pensar. Encontramos, além disto, em português e espanhol, uma variante para o mesmo provérbio:

Nenhum dedo faz mão, nem uma andorinha faz verão.

$\mathrm{Ni}$ un dedo hace mano, ni una golondrina verano. 
3. Cada asno com seu igual,

Pari con pari, ben sta e dura.

4. Lé com lé, cré com cré, cada um com sua ralé.

Tal guaina, tal coltello.

Os provérbios em português se apresentam em linguagem bem oral, até mesmo grosseira, como "asno" e "ralé". As expressões "lé com lé, cré com cré" parecem-nos só funcionar como rima.

Em língua italiana os ditados correspondentes têm cunho erudito pertencendo a outro nível de linguagem.

\section{Bode}

5. Para quem ama, catinga de bode é cheiro.

Ogni naso par bello alla sua faccia.

var/ Quem ama o feio bonito lhe parece.

Os provérbios exprimem o mesmo conceito, usando de imagens diferentes. O português, em sua primeira formulação, soube encontrar uma expressão tão feliz e direta, mesmo na sua vulgaridade.

\section{$C \tilde{a} o$}

6. Um cão mordido, todos o mordem.

A caval fiaco, ghe va drio le mosche (A un cavallo indebolito gli van dietro le mosche)

Apesar de serem usados animais diferentes, os provérbios apresentam o mesmo conceito, porém o dialeto vêneto parece-nos mais espontâneo e direto do que o português.

7. Quem seu cão quer matar, raiva the põe nome.

Chi il suo cane vuole ammazzare, qualche scusa sa pigliare.

No caso do cão de que seu dono quer se livrar, o português se prende ao francês "qui veut noyer son chien, l'accuse de la rage" que Molière cita em sua obra Les Femmes Savantes (II, 5). 
A expressão em português parece-nos mais feliz por usar a doença mais comum desta espécie animal, enquanto que o italiano fala de modo genérico, "qualche scusa sa pigliare" causando menos impacto.

8. Tanto vai o cão ao moinho que um dia lá deixa o focinho.

Tanto va la gatta al lardo che ci lascia lo zampino.

O provérbio italiano é bem mais natural e lógico quando fala de uma gata que vai atrás do toucinho. O português com a substituição da "gata" pelo "cão", tem algo de artificial: por que iria o cão ao moinho? Só pela rima?

De se notar também, a variante portuguesa "Tantas vezes vai o cântaro à fonte até que quebra" ou "Tanto vai o pote à bica que um dia lá se fica" que expressa o mesmo conceitõ com imagens diferentes, mais requintadas.

\section{Cavalo}

9. A cavalo dado não se olham os dentes.

var/ A cavalo dado não se abre a boca.

A caval donato non si guarda in bocca.

Em ambas as línguas fala-se da idade do cavalo, cuja verificação se faz pela observação da dentadura, sendo que o português é mais preciso, usando o vocábulo "dentes", quando o italiano emprega "boca", como na variante portuguesa assinalada.

\section{Escaravelho}

10. O escaravelho a seus filhos chama grãos de ouro.

Ogni scarafone è bello a mamma soia (Ogni scarafaggio par bello alla sua mamma) - dial. napolitano.

Nestes anexins é enaltecido o amor dos animais para com sua prole. O italiano apresenta, além desta, outra formulação: "Ad ogni uccello suo nido è bello", sem correspondente em português, mas encontrado em francês, espanhol, alemão e inglês, onde o vocábulo "ninho" pode ser interpretado como a ninhada, ou seja, 
a prole. Por outro lado o correspondente latino "Sua cuique patria jucundissima" dá margem a outra interpretação, considerando "ninho" como casa; e por extensão, pátria.

\section{Galinha}

11. De grão em grão a galinha enche o papo.

A granello a granello s'empie lo staio e si fa il monte.

Para indicar a antiga e sempre nova motivação à poupança, o português apresenta esta gostosa expressão com sabor de campo, que tem a mesma forma em espanhol e em inglês, enquanto que o italiano, apesar de empregar também a imagem da semente, não possui igual força de expressão.

12. Mais vale o ovo hoje do que a galinha amanhã.

E' meglio oggi l'uovo che doman la gallina.

Existe uma perfeita correspondência entre as duas línguas, sendo que o português apresenta também o sugestivo "Antes um pássaro na mão do que dois voando" onde o conceito da posse imediata de uma ave hoje, em lugar de duas amanhã, tem mais força de expressão do que o primeiro provérbio.

\section{Gato}

13. Gato escaldado tem medo de água fria.

Gatto scottato dall'acqua calda, ha paura della fredda.

Ambos os provérbios não necessitam comentários, usando a mesma formulação, o que acontece também em outra línguas modernas, como o francês e o espanhol.

O que nos parece interessante notar é a existência de duaș variantes na língua portuguesa, uma usando o mesmo animal, o "gato", mas introduzindo como causa do medo, em lugar da água quente, outro animal, a "cobra": "Gato mordido de cobra tem medo de corda", e "Quem foi mordido de cobra tem medo até de minhoca". No primeiro pode-se notar a assonância entre as palavras cobra" e "corda" e a eficácia da imagem da "corda" que imita a forma da "cobra". 


\section{Papagaio}

14. Papagaio come milho, periquito leva a fama.

Altri hanno mangiato la candela e tu smaltisci lo stoppino. var/ Uno fa i miracoli e un altro raccoglie i moccoli.

Muitas vezes na vida não é quem pratica uma ação que recebe o louvor ou a reprimenda, mas outro qualquer. O português e o italiano têm ambos provérbios singulares e saborosos a respeito do tema. Os ditados em língua italiana, encontrados em uma coletânea de provérbios toscanos, recendem a sacristia (é famoso o espírito sacrílego dos toscanos). O português, no entanto, apresenta duas aves características no Brasil, o papagaio e o periquito.

\section{Peixe}

15. Filho de peixe peixinho é.

Chi di gallina nasce convien che razzoli.

Provérbios que significam a mesma coisa com formulações diferentes, recorrendo porém ambos a animais. O italiano parece-nos mais rebuscado, usando uma perífrase em lugar da palavra "filho", como acontece no português que é mais direto e mais curto, usando o recurso da repetição de palavras ("peixe", "peixinho"), muito eficaz.

\section{Pepino}

16. $\widehat{\mathrm{E}}$ de pequenino que se torce o pepino.

Finché la pianta è tenera bisogna drizzarla.

$\mathrm{O}$ antigo ditado latino "Est arbuscula, non truncus curvandus in uncium" que 0 italiano, assim como o inglês e o alemão, traduz ao pé da letra, encontra no português uma expressão mais própria, exemplificando com um tipo de vegetal tão comum no Brasil que, além disto, oferece rima para "pequenino". 


\section{Porco}

17. Quem com porcos se mistura farelo come.

Chi pratica col lupo impara a urlare.

var/ Chi pratica lo zoppo impara a zoppicare.

O italiano apresenta duas formulações da mesma idéia, uma usando um animal ("lobo") símbolo de agressividade, a outra o portador de um defeito físico.

O português usa um animal não muito nobre, famoso por sua glutoneria, onde se justifica o verbo "comer". Deve-se notar também que os três verbos que indicam as ações praticadas (comer farelo/urrar/mancar) são depreciativos.

\section{Raposa}

18. A raposa muda de pele, mas não de manha.

La volpe (il lupo) perde il pelo, ma il vizio mai.

Enquanto o latim e a maioria das línguas usa o "lobo" para este mesmo provérbio, o italiano e o português usam "raposa". O italiano, também com uma variante "lobo", fala em vício, ao passo que o português usa o vocábulo "manha", menos forte e, a nosso ver, mais próprio para a raposa, animal conhecido por sua astúcia. O espanhol e o inglês, em lugar de "pele", usam "dentes" (Muda el lobo los dientes y nos las mientes) quase a mostrar a arma poderosa com que a natureza o dotou.

\section{Sapo}

19. A necessidade faz o sapo pular.

Necessità è madre delle arti.

O provérbio italiano traduz ao pé da letra o latim "Mater artium necessitas", assim como o fazem outras línguas modernas. $\widehat{\mathrm{E}}$ bastante expressivo, primando pela concisão e com um toque clássico. O português, ao contrário, tem cunho popular e, portanto, é de aceitação mais ampla. 


\section{Sardinha}

20. Puxar a brasa para sua sardinha.

Ognuno tira l'acqua al suo mulino.

O italiano se inspira na prática agrícola, ao passo que o português retrata um grupo de pessoas que, com um pouco de fantasia, poderíamos imaginar após a pesca, ou a caça, ao redor de uma fogueira, competindo para assar sua magra refeição.

\section{II - HOMEM-MULHER}

\section{Mulher}

21. A mulher e a vaca busca atrás da casa.

Moglie e buoi dei paesi tuoi.

As duas línguas exprimem o mesmo conselho, isto é, de se casar com mulher conhecida. Enquanto o italiano fala com mais amplitude, o português usa a expressão "atrás da casa", como a indicar a preservação do lar.

Não interpretamos a comparação da mulher com o gado como depreciativa, levando em conta que se trata de um ditado provavelmente originário dos campos, em que a vaca é considerada animal de grande valia.

A este propósito lembramo-nos do poema de Umberto Saba "A mia Moglie":

... Tu sei come una gravida

giovenca;

lieta ancora senza

gravezza, anzi festosa;

che, se la lisci, il collo

volge, ove tinge un rosa

tenero la sua carme... 
22. Nas mulheres confiar é tomar em rede o vento.

23. Mulheres e príncipes só a vontade os obriga.

24. Mulher mesquinha debaixo da escama acha a espinha.

25. O homem fogo; a mulher estopa; vem o Diabo e assopra.

26. A mula e a mulher com pau se quebra.

27. Le donne hanno lunghi i capelli e corti i cervelli.

28. Donna e luna, oggi serena e domani bruna.

29. Un uomo di paglia vale una donna d'oro.

30. Le parole sono femmine, e i fatti son maschi.

O português e o italiano têm, dentro deste tema, grande número de provérbios que podem ser considerados como simples traduções e que, portanto, escapam ao nosso estudo. Nos ditados citados acima prevalece um claro desprezo pela mulher, que é apenas um objeto de utilidade doméstica ou um mal necessário. Sua inferioridade em relação ao homem é sempre apontada com crueldade, quando a Bíblia dela fala usando expressões altamente elogiosas, como no livro Provérbios (31/10) "Quem achará uma mulher forte? Seu preço excede a tudo o que vem de remontadas distâncias, e dos últimos confins da terra. O coração de seu marido põe nela a sua confiança, e ele não necessitará de despojos..." (3)

Merece destaque nos provérbios acima a elegância do português arcaico $\left(n^{\circ} 22\right)$, a felicidade da imagem do $n^{\circ} 25$ e o refinamento sintético do $\mathrm{n}^{\circ} 28$.

III - FAMÍLIA

\section{Madrasta}

31. A ociosidade é madrasta das virtudes.

L'ozio è il padre di tutti i vizi.

Os ditados acima diferem quanto à sua formulação. O português usa o vocáculo "madrasta" no sentido de inimiga, ao passo que o italiano emprega a palavra "padre", não levando em conta seu valor afetivo, mas como o procriador. 


\section{Parentes}

32. Meus parentes são os dentes.

var/ Mais perto estão os dentes que os parentes.

33. Fratelli coltelli, parenti mordenti.

var/ Fratelli flagelli.

34. Entre paí e irmãos não metas as mãos.

35. Chi vuol viver e star sano, da' parenti stia lontano.

varf Meglio un prossimo vicino che un lontan cugino.

36. Val più un amico che cento parenti.

37. Amici a scelta e parenti come sono.

Abundam os provérbios em italiano sobre o tema, sem correspondência precisa em português. Ambas as línguas, porém, usam a imagem dos "dentes", o português querendo significar que os dentes são mais importantes do que os parentes, o italiano introzindo a idéia de que os parentes mordem, atacam, são como as armas de defesa dos animais.

\section{Padrinho}

38. Quem tem padrinho não morre pagão.

Chi no ga santoli, no ga buzolai (Chi non ha padrini, non ha ciambelle).

O português possui uma feliz expressão no âmbito da fé católica, chegando à condenação definitiva "morre pagão". O dialeto vêneto se vale da gula para dar força ao conceito de que o protegido recebe sempre o melhor quinhão, ditado que encontra seu correspondente em português "O pão do meu compadre grande pedaço a meu afilhado".

Provérbios em moda hoje em dia, como no tempo passado! 


\section{IV - PÁTRIA}

\section{Pátria}

39. Todo lugar é pátria para o sábio. (var/ forte).

Ogni paese al galantuomo é patria (var/ valentuomo)

40. Toda a terra é nossa pátria.

La patria è dove s'ha del bene.

Os provérbios de no 39 são correspondentes, variando apenas os termos "sábio" (com a variante "forte"), e "galantuomo" (com a variante "valentuomo") .

Quanto aos de $\mathrm{n}^{\circ} 40$, o português é mais abrangente, querendo significar que qualquer lugar pode ser considerado pátria, enquanto o italiano restringe a idéia ao lugar onde se está bem.

\section{$\mathrm{V}$ - LUCRO}

\section{Moeda}

41. Tostão a tostão faz um milhão.

Di quattrino in quattrino si fa il fiorino.

Existe nas línguas as mesmas imagens (moedas) como estímulo à parcimônia (ver também o $n^{\circ}$ 11) .

42. Pagar com a mesma moeda.

Render pan per focaccia.

Retribuir o bem com o mal é expressado em português com - símbolo do dinheiro, em italiano com o símbolo do principal alimento humano em sua forma comum (pane) e em sua forma achatada (focaccia) definida no Zingarelli (16) desta maneira: "pane schiacciato messo a cuocere in forno o sotto la brace". 


\section{VI - VELHICE}

\section{Velhice}

43. Velhice é mal desejado.

La vecchiezza da ognuno è desiata, quando s'acquista viene odiata.

Ambos os provérbios encerram o mesmo conceito, sendo que o italiano acrescenta-lhe "quando s'acquista viene odiata", de rima fácil e com sabor de coisa antiga, um tanto démodée.

VII

- POBREZA/RIQUEZA

Pobre-/Rico

44. Melhor é o pobre justo que o rico mentiroso.

Meglio povertà onorata, che ricchezza svergognata.

45. Pobreza e alegria nunca dormem na mesma cama.

Riccheza e scienza insieme non hanno residenza.

O conceito é o mesmo nos provérbios de $n^{\circ} 44$, com a diferença que o italiano parece-nos mais indefinido, mais vago. Além disto, enquanto o italiano usa um par de adjetivos contrários ("onorata", "svergognata"), o português não emprega antônimos, mas "justo" e "mentiroso". No $2^{\circ}$ grupo (n' 45) a imagem da coabitação é expressa nas duas línguas de modo diverso: o italiano usa a palavra "residenza", o português "cama", parecendo-nos mais direto e mais popular.

\section{VIII - RELIGIÃO}

\section{Deus}

46. Deus dá o frio conforme o cobertor.

Dio manda il freddo secondo i panni.

var/ Dio misura il vento all'agnello tosato. 
A idéia de que Deus provê às necessidades de suas criaturas tem seu paralelo nas duas línguas. A variante acima "Dio misura il vento all'agnello tosato" parece-nos digna de ser mencionada por seu doce e gentil sabor bucólico.

47. Quando Deus fecha uma porta abre uma janela.

Non si serra mai una porta che non se ne apra un'altra.

var/ Idio sera un balcon e el verzi un porton (dialeto vêneto:

Dio chiude una finestra, ma apre un portone).

As expressões são correspondentes, mas o italiano só fala de "porta", ao passo que o português introduz o elemento "janela", quase a título de compensação. O dialeto vêneto parece ir mais além com as expressões "balcon" e "porton" querendo talvez significar que a misericórdia divina dá mais do que uma compensação.

\section{Diabo}

48. Acender uma vela a Deus e outra ao diabo.

Accendere una candela a Dio e due al diavolo.

Sobre o tema os vários povos têm muitos provérbios e todos gostosos. Escolhemos os que nos pareceram mais significativos ou curiosos. Note-se que enquanto o português aconselha a acender uma vela ao diabo e outra a Deus, o italiano é ainda mais cauteloso: duas ao diabo e uma a Deus.

49. Comer o pão que o diabo amassou.

La farina del diavolo va tutta in crusca.

50. Chi vuol mangiar col diavolo, bisogna aver cucchiaio lungo.

51. Il diavolo fa le pentole e non il coperchio.

Este grupo de provérbios não tem uma correspondência perfeita, mas um elemento que aparece em todos eles é relacionado com comida: "pão", "amassou", "farina", "comer", "mangiare", "cucchiaio", "pentola".

Merece destaque pela imagem pouco comum o de $n^{0} 50$, assim como por suas incorreções gramaticais. 


\section{Vinho}

52. O vinho alegra o coração do homem.

Vino non é buono che non rallega l'uomo.

53. O vinho não tem leme.

Quando Bacco trionfa, il pensier fugge.

Observações velhas como o homem são as que dizem respeito ao vinho e às consequiências do seu abuso. Os latinos já diziam "in vino veritas" ou "dum vinum intrat, exit sapientia" que nos lembram comentários de scriba de manuscritos monásticos medievais e cantos humorísticos de estudantes universitários. Foram os arquétipos da maioria dos ditados sobre o tema, inclusive os italianos e portugueses.

Escolhemos para cotejar apenas alguns que achamos mais significativos, mesmo sem possuir cunho de originalidade.

\section{$\mathrm{X}$ - ANATOMIA}

\section{Boca}

54. Quem tem boca vai a Roma.

Chi lingua in bocca ha, a Roma va.

Apesar da aparente semelhança, o italiano parece-nos mais preciso e mais direto, porque pode-se ter boca e não falar; a língua é o importante!

\section{Perna}

55. A mentira tem pernas curtas.

Le bugie hanno le gambe corte.

56. Mais depressa se pega um mentiroso do que um coxo. Le bugie sono zoppe. 
A mentira e o mentiroso parecem ter sempre despertado o interesse popular. Os latinos usavam o austero "nullum mendacium veterascit", onde o verbo incoativo indica a ação de envelhecer. As línguas modernas usam como termo de comparação o vocábulo "pernas", mas enquanto o espanhol e o inglês dizem "não têm pernas", o português e o italiano usam "têm pernas curtas", e o provérbio de $\mathrm{n}^{\circ} 56 \mathrm{diz}$ "têm pernas defeituosas", ao qual corres" ponde o outro provérbio português com a imagem do "coxo".

\section{Tripa}

57. Fazer das tripas coração.

Far stringhe della propria pelle.

Para mostrar que, às vezes, a vida pode ser cruel e que é preciso adaptar-se às circunstâncias, o português usa uma expressão caracteristicamente popular, muito mais eficaz do que o italiano. Interessante notar que ambas as línguas, apesar de não empregarem palavras correspondentes ("tripa" e "stringa" = cam darço) exprimem o mesmo conceito. De fato, o que é tripa senão uma tira comprida que lembra, em sua forma, um cadarço?

\section{XI - PROFISSÕES}

\section{Ferreiro}

58. Casa de ferreiro, espeto de pau.

In casa di calzolaio non si hanno scarpe.

Ambos os provérbios dão o mesmo conselho: que, em "casa" de especialistas, não há que procurar o objeto de seu trabalho. Para isto o português usa a arte do ferreiro, o italiano a do remendão.

\section{Médico}

59. O enfermo impaciente faz o médico ser cruel.

L'ammalato disubbidiente fa il medico crudele. 
60. Mal prolongado, morte no cabo.

Malattia lunga, morte sicura.

Dentre os muitos anexins dedicados ao médico e às doenças, desde os tempos mais antigos, transcrevemos alguns poucos para mostrar o paralelismo entre o português e o italiano.

\section{Romeiro}

61. Não há romeiro que diga mal do seu bordão.

Tra il cuoco e il canovaccio non è mai inimicizia.

As duas línguas usam formulações diferentes para exprimir a mesma idéia: dois profissionais que dão o devido valor ao objeto que os auxilia.

\section{XII - VÄRIOS}

\section{Emenda}

62. Pior a emenda do que o soneto.

Pezo el tacon che el buso (Peggio il rammendo del buco) var/ Meglio buttar via che rammendare.

Encontram-se inúmeras contradições nos ditados populares; enquanto alguns deles enaltecem a poupança (ver n's 11 e 41) há outros, como os citados acima, que pregam o contrário, pois é bem verdade que "cada cabeça cada sentença".

O dialeto vêneto, com seu gostoso sabor popular, faz contraste com o literário "pior a emenda do que o soneto" que sabe a tertúlias e academias.

\section{Fama}

63. Cria fama e deita na cama.

Fatti un buon nome e piscia a letto, e' diranno che hai sudato (toscano). 
As duas línguas usam a mesma imagem, a "cama", para representar o repouso e a preguiça, mas o toscano vai mais além, empregando um termo até mesmo vulgar, mas que torna o provérbio mais completo e até divertido.

\section{Ferro}

64. Quem com ferro fere, com ferro será ferido.

Chi di coltel ferisce, di coltel perisce.

var/ Chi la fa, l'aspetti.

Os antigos latinos já usavam o sempre citado "qui gladio ferit, gladio perit" que, na formulação alemã conservou o mesmo vocábulo Schwert (espada). No português e no espanhol preferiu-se o termo mais genérico "ferro" que, no francês e no italiano virou faca ("coltello").

Como se vê, partiu-se dos "romances de capa e espada" para chegar à crônica policial de jornais populares.

\section{Perfume}

65. Os melhores perfumes estão nos frascos pequenos.

Le spezierie migliori stanno nei pacchetti piccoli.

Os dois provérbios parecem-nos ter origens remotas: o primeiro de costumes refinados das cortes européias, o outro da febre das grandes viagens marítimas em busca das preciosas especiarias.

Queda

66. Quanto mais alto se sobe maior queda se dá.

var/ Quem sobe depressa, depressa cai.

Chi troppo in alto sal-cade sovente precipitevolissimevolmente.

Interessante notar neste grupo que o italiano, querendo indicar uma queda muito rápida, compõe um originalíssimo advérbio de 26 letras, não registrado nos dicionários. 
Como nos propusemos no início, apresentamos, agora, uma listagem de provérbios para os quais não encontramos correspondência em uma das duas línguas.

67. A macaco velho não se ensina a fazer careta.

68. Cada macaco no seu galho.

69. Macaco não enxerga o seu rabo, mas enxerga o da cotia.

70. Macaco velho não mete a mão em combuca.

71. Macaco velho não pula em galho seco.

72. Papagaio velho não aprende a falar.

73. Praga de urubu não mata cavalo.

São inúmeros os provérbios em português que dizem respeito a animais, provavelmente em sua maioria brasileiros, que retratam a fauna tropical. Assim, não poderiam ter correspondentes em italiano.

Todos eles são gostosos, de cunho popular, predominando os que dizem respeito ao macaco, célebre por suas travessuras e esperteza. A propósito do anexim de $n^{0} 70$, Rodolpho von Ihering em seu famoso Dicionário dos Animais do Brasil (7) comenta: “.. o macaco metendo a mão em certa vasilha de bocal estreito, e presa ao solo, cheia de milho, se deixa aí prender, quando, enchendo dentro a mão com milho e, engrossando esta, não pode sair pelo bocal em que coube vasia; de modo que o sôfrego macaco, não se lembrando de soltar o milho, para poder retirar a mão vasia, fica aí preso, até que chegam os que lhe armaram a ratoeira".

Além dos provérbios brasileiros que se referem a animais, ocorreram-nos vários outros, dentre os quais:

74. Quem conta um conto aumenta um ponto.

75. Ladrão que rouba ladrão tem cem anos de perdão.

76. O uso do cachimbo faz a boca torta.

77. Mais vale um gosto que dois vinténs. 
Do mesmo modo, também em italiano, anotamos alguns provérbios sem correspondência em português:

78. Avuta la grazia gabbato lo santo.

var/1/ Passata la festa gabbato lo santo. $\operatorname{var} / 2 /$ Opera fatta maestro in pozzo.

79. Non bisogna fasciarsi il capo prima di romperselo.

80. Molte mani fanno l'opera leggera.

var/ Molte man fa presto el pan (dialeto vêneto).

Estas as observações que julgamos interessante apresentar, ao comparar provérbios em português e italiano. Não temos a pretensão, com isto, de ter esgotado o assunto mas, simplesmente, de ter iniciado um tipo de estudo que gostaríamos de continuar desenvolvendo, com ajuda e sugestões que, por ventura, viermos a receber.

\section{BIBLIOGRAFIA}

1. ARTHABER, Augusto. Dizionario comparato di Proverbi e Modi Proverbiali italiani, latini, francesi, spagnoli, tedeschi, inglesi e greci antichi con relativi indici sistematico-alfabetici. Milano, Hoepli, 1981. $892 \mathrm{p}$.

A primeira edição deste Dizionario data do ano 1929, é obra indispensável para qualquer estudo comparativo de ditados nas várias línguas indicadas no título. $\overline{\mathbf{E}}$ organizado em ordem alfabética da palavra chave.

2. BELLONZI, Fortunato. Proverbi toscani. Firenze, Martello-Giunti, 1975. $184 \mathrm{p}$.

Coletânea de 2.632 provérbios toscanos, reunidos por tema, com uma interessante introdução do Autor e uma breve bibliografia. E complemento da famosa coletânea que o poeta Giuseppe Giusti publicou há mais de um século (1873).

3. BibliA Sagrada. Trad. Pe. Antônio Pereira de Figueiredo. s. 1., Barsa, 1965. $1366 \mathrm{p}$.

E o texto bíblico publicado pela Catholic Press, com texto, notas, ilustraçōes a cores, páginas não numerađas para anotações do proprietário. No final do volume um Dicionário Prático de cultura católica, biblica e geral, que é tradução do Catholic Dictionary incluso nas Bíblias publicadas em lingua inglesa. 
4. BONFIM, Celso. Bella morettina, ciao! Estado de Minas, Belo Horizonte, 14 out. 1981 .

O autor deste artigo escreve sobre a influência dos imigrantes italianos na cultura e nos costumes mineiros. Relembra muitos ditados italianos e dialetais que tenta traduzir para o português ou compara, com alguns existentes no Brasil.

5. FERREIRA BUARQUE DE HOLANDA, Aurélio, Novo Dicionário da Lingua Portuguesa. Rio de Janeiro, Nova Fronteira, s.d., 1517 p.

6. CASANOVAS, Carlos Francisco de Freitas. Provérbios e frases proverbiais do século XVI. Brasilia, INL, 1973. 511 p. (Coleção Consulta Cientifica, 3).

Trata-se de uma obra erudita que reüne adágios portugueses do século XVI colhidos na literatura, deste periodo.

7. IHERING, Rodolpho von. Dicionärio dos Animais do Brasil. São Paulo, Secretaria da Agricultura, Indústria e Comércio do Estado de São Paulo, 1940. 898 p.

Obra bem conhecida e preciosa do naturalista de ascendência "alemã. Foi publicada após a morte do Autor e era distribuida gratuitamente, hoje só encontrada nos «sebos». Tem quadros sinóticos da fauna brasileira e fornece utteis e curiosas informações sobre a vida e os costumes dos animais brasileiros. Organizado segundo ordem alfabética dos nomes vulgares, possui também um glossário dos nomes genéricos e específicos com a nomenclatura binária.

8. MANZONI, Alessandro. I Promessi Sposi. Torino, UTET, 1944, (Coleção Classici Italiani con note, 5).

9. MARONI, Matizia Lumbroso. Proverbi e modi di dire trascritti e illustrati da bambini italiani e stranieri. Roma, F'ondazione Ernesta Besso, 1971. $398 \mathrm{p}$.

Uma curiosa e sugestiva coletânea de provérbios escolhidos, definidos e comentados por crianças italianas e estrangeiras. O Brasil também está representado, mas com apenas duas páginas.

10. MOTA, Mauro. Os bichos na fala da gente. 2 ed. Rio de Janeiro, Tempo Brasileiro, 1978. $204 \mathrm{p}$.

11. NASCENTES, Antenor. Tesouro da Fraseologia Brasileira. 2 ed. Rio de Janeiro, Freitas Bastos, 1966. $316 \mathrm{p}$.

O Professor Antenor Nascentes, autor de tantos estudos sobre o idioma nacional, reuniu neste volume frases e ditados em lingua portuguesa, dos quais explica a origem e o significado.

12. PROVENZAL, Dino. Perché si clice cosí? Milano, Hoepli, 1966. 347 p. A preciosa - e divertida - obra de Provenzal trata mais de ditos famosos do que propriamente de adágios. Fornece a origem das frases italianas e de algumas latinas que ainda são citadas na Itália. 
13. ROHLFS, Gerhard. Studi e ricerche su Lingua e Dialetti d'Italia. Firenze, Sansoni, 1972. $414 \mathrm{p}$.

O conhecido linguiista que na introdução declara «sentir-se ligado à companhia dos historiadores a serviço de uma lingüilstica que, enquadrada na história social e cultural, se transforma em história» nos apresenta um interessantíssimo estudo comparativo dos vários dialetos italianos.

14. TOMMASEO, Nicolò. Dizionario della lingua italiana. Torino, UTET, 1879.

15. VERGA, Giovanni, I Malavoglia. Verona, Mondadori, 1964. 294 p. (Coleção Biblioteca Moderna Mondadori, 288).

A obra prima de Giovanni Verga, um dos maiores romancistas italianos do século passado.

16. ZINGARELLI, Nicola. Vocabolario della lingua italiana. 7 ed. Bologna, Zanichelli, 1951. $1723 \mathrm{p}$. 